\title{
Mental Health Promotion Efforts for Children and Youth in Canada and Beyond: Evidence in Research, Policy, and Practice
}

\author{
Jessica Whitley, Suzanne Gooderham \\ University of Ottawa
}

\begin{abstract}
Mental health issues continue to present barriers for Canadian children, in terms of both psychological and academic outcomes. Growing numbers of students are placed "at risk" as a result. A mental health promotion approach suggests that students can develop a number of skills and competencies, namely those related to social-emotional learning (SEL), which can reduce their chance of developing mental health difficulties. In Canada, a wide range of curricula, frameworks, initiatives, and programs have been put in place that address elements of SEL. In this paper, a sampling of these drawn from across the country is described. The emphasis on SEL apparent in many provinces and territories is evidence of the shared understanding of its importance with respect to improving student outcomes. However, a lack of evidence to support these approaches, inconsistencies in terms of terminology and practices, the lack of alignment between SEL and academics, and the piecemeal approach adopted within some provinces leave SEL and mental health promotion approaches vulnerable to being labelled "add-ons" and becoming transient initiatives.
\end{abstract}

Many students in Canadian schools are struggling to succeed academically and socially due to ongoing and significant mental health issues. According to the Canadian Coalition for Children and Youth Mental Health, the mental health of students is the "number one issue facing schools today" (Brown, 2011, p. 1). Although estimates vary widely, the percentage of children and youth experiencing mental health difficulties, including anxiety and depression, is suggested to be between $15 \%$ and $30 \%$ and is growing (Arboleda-Flórez, 2005; Leitch, 2007; Roberts, Stuart, \& Lam, 2008; Waddell \& Shepherd, 2002). 
Students with mental health difficulties are considered "at risk" for a number of negative long-term outcomes. This group of students is more likely to experience lower academic achievement, less school engagement and participation, poorer peer and family relationships, and are more likely to drop out of school (Meldrum, Venn, \& Kutcher, 2009; Vaillancourt \& Boylan, 2013; Volk, Craig, Boyce, \& King, 2006). Long-term outcomes, including employment and education, are also significantly poorer for individuals with mental health difficulties than for those without (Fergusson \& Woodward, 2002).

Rather than simply the absence of mental illness, mental health is most often currently defined as encompassing social and emotional competence and well-being. According to the World Health Organization (WHO), mental health can be defined as "state of well-being in which an individual realizes his or her own abilities, can cope with the normal stresses of life, can work productively and is able to make a contribution to his or her community" (World Health Organization, 2014, para. 1). The WHO stresses that health in general is a state of well-being rather than the absence of disease. The Public Health Agency of Canada defines mental health as "the capacity for each of us to feel, think and act in ways that enhance our ability to enjoy life and deal with the challenges we face" (2012).

The interplay between mental health difficulties and academic difficulties, both in terms of identification and intervention, is a complex one. Research findings have suggested that those with higher social-emotional competencies (e.g., coping, relationship, and problem-solving skills; self-control) develop better long-term mental health (Durlak \& Wells, 1997; Greenberg, Domitrovich, \& Bumbarger, 2001; Taylor \& Stanton, 2007) and perform at higher academic levels than those with fewer skills in the area (Payton et al., 2008; Snyder et al., 2009; Zins, Bloodworth, Weissberg, \& Walberg, 2007). These competencies allow students to learn from and work with peers, build positive relationships with teachers and parents, display positive classroom behaviours, and persevere in the face of academic difficulties; all of which facilitate success in school (Zins et al., 2007).

Within school systems, teachers and early childhood educators who are working with young children often focus on development and well-being with an equal focus on social, emotional, behavioural, and academic skills (Hemmeter, Ostrosky, \& Fox, 2006; Howes et al., 2008; Rimm-Kaufman, Pianta, \& Cox, 2000). Thus the positive mental health of students is supported and facilitated alongside more traditional pursuits of reading and mathematics. As children move through elementary grades, however, an increased focus on mastery of curricular expectations emerges; and a process of assessment and identification of students who fail to achieve at levels similar to their peers takes place (Ranz-Smith, 2007). The social and emotional needs of students and their ever-developing mental health, which are inextricably linked to their academic success, are often set aside as the "real work" of school takes precedence (Elias, 2009; Ranz-Smith, 2007).

While high-level policies do reflect an understanding of the need to focus on mental health, and the recognition of the role of holistic development, these are often in competition with accountability frameworks and a narrow academic focus (Elias, 2009). 
A focus on preventing later difficulties by promoting the multi-faceted development of students is not a priority in many North American schools and classrooms, particularly in higher grades. However, this prevention perspective is evident in recent research literature. According to Schonert-Reichl and Stewart Lawlor (2010),

as increased research attention to the promotion of children's social and emotional competence in schools has come to the fore in the past decade, a paradigm shift in psychology has been unfolding with recent years witnessing a shift from a preoccupation with repairing weaknesses to the enhancement of positive qualities and preventing or heading off problems before they arise (138).

In research and practice, then, a focus on social and emotional competencies across grades, and on the promotion of mental health rather than solely a deficit-based, intervention-focused approach is warranted in order to improve both mental health and academic outcomes. The current paper will examine research related to the efficacy of mental health promotion efforts, including a specific focus on social-emotional learning (SEL). Approaches to the implementation of SEL in schools across Canada, evidenced largely in policy documents, will also be analyzed with respect to alignment with a health-promotion and SEL-focused approach.

\section{Health-Promotion Approaches}

A focus on general health promotion has been a key element of health care systems in many countries for decades. In 1986, the WHO organized the First International Conference on Health Promotion in Ottawa, Canada. The Ottawa Charter for Health Promotion emerged from this meeting, which defines health promotion as "the process of enabling people to increase control over, and to improve, their health" (p. 1). The charter highlights the need to (a) build healthy public policy, (b) create supportive environments, (c) strengthen community actions, (d) develop personal skills, and (e) reorient health services (Cameron \& Kerner, 2013). Reviewing the conceptual and empirical foundations of health promotion is far beyond the scope of this paper. However, there are elements of this broader approach to improving health that are of particular relevance for the current discussion.

Research and practice based in the WHO's perspective on health promotion typically emphasize a socio-ecological approach to health promotion with the understanding that health is not solely determined by an individual; there is instead a recognition of the many elements of environments that support and facilitate health (Kickbusch, 2003; McLeroy, Bibeau, Steckler, \& Glanz, 1988; Minkler, 1989). This shifts the responsibility for health from individuals, to include the broader community including health-care professionals and governmental organizations. The Public Health Agency of Canada, as an example, has as its mandate health promotion as well as prevention and control of disease (www.phac-aspc.gc.ca). Within its health promotion portfolio, this agency has programs devoted to encouraging immunization among children, preventing family violence, promoting healthy pregnancies, encouraging use of the Canada Food Guide, and preventing obesity.

Prevention and promotion approaches are also evident in research surrounding youth at risk, including programs focused on reducing or eliminating smoking, drug and alcohol 
use, and unplanned pregnancies. While many of these programs also put the focus on the choices and behaviours of individuals, many also adopt a more multi-faceted health promotion perspective, including an emphasis on social influences (e.g., DeJong \& Langford, 2002; Hoyt \& Broom, 2002).

\section{Mental Health Promotion}

The application of mental health promotion, as a preventative approach, has been the focus of many community and school-based initiatives. As with health broadly, a socioecological approach views mental health as an individual developmental process but is also "conditioned by specific neighbourhood, school and community influences that intersect with families, peers and individuals" (Zubrick \& Kovess-Masfety, 2005, p. 150). Thus an individual's mental health is not solely determined by the individual, their genetic makeup, and temperament but is in part a product of the environment in which they live. This perspective allows for the possibility of interventions or influences that can impact an individual's psychological well-being.

A number of studies have explored the efficacy of mental health promotion programs on children and adolescents. A review by Wells, Barlow, and Stewart-Brown (2003) synthesized findings from 17 largely U.S.-based studies and included programs focused on conflict resolution, prosocial and antisocial behaviour, prevention of depression and suicide, promotion of self-esteem or self-concept, and emotional literacy. Measured outcomes include depressive symptoms, self-esteem, self-concept, problemsolving strategies, anxiety, and externalizing behaviours. The interventions focused at the elementary level (the majority) were typically broader and more skill-based; those at the middle and secondary level included a specific focus on issues such as depression and suicide. Many more studies were identified by authors as being relevant to the topic of mental health promotion; most, however, failed to meet the inclusion criteria, which included a control condition and detailed reporting on the number of participants and their comparability prior to the intervention. In fact, there is a real dearth of rigorous evaluations of the many programs and interventions focused on mental health promotion.

In analyzing findings from the 17 studies, Wells et al. (2003) found that most showed some positive results. The programs most likely to show efficacy were mental health-promoting programs (as opposed to illness prevention), which were provided continuously over extensive periods of time (a year or longer). Support was also found for programs that adopted whole-school approaches that included students, staff, families, and community and that focused on changes in the environment (e.g., a school-wide focus on non-violent conflict resolution) rather than simply on changing the behaviours of individual students. Given the wide range of program types, delivery models, and study populations included in the analysis of Wells et al., resulting in few comparisons, these findings represent trends rather than firm conclusions.

Further support for many of the findings of Wells et al., however, is evidenced in later studies and reviews. As with the broader health promotion literature, findings from studies focusing on mental health promotion have indicated a need for an ecological, environmental approach that targets change and support at multiple levels, rather than simply the individual (e.g., Stewart-Brown, Patterson, Mockford, Barlow, \& Pyper, 2004; 
Weare \& Markham, 2005; Weare \& Nind, 2011). However, varied methodologies as well a focus on short- rather than long-term outcomes continue to present issues in generalizing findings.

In addition to a multi-level, ecological approach that is a hallmark of effective health promotion, the existence of many programs and interventions being introduced at the elementary level also reflects a belief in the role of prevention. The mental health field has traditionally been more focused on illnesses which tend to emerge later in adolescence. Logically then, interventions are more often focused at the middle-school or secondary level (e.g., Chisholm, Patterson, Torgerson, Turner, \& Birchwood, 2012).

Many programs and approaches being investigated - indeed the majority described in the Wells et al. (2003) review-are in fact focused on younger children, between the ages of 6 and 12 years. The theory underlying these programs is that if children can develop and maintain social-emotional skills, these will prevent the development or exacerbation of mental health difficulties and potentially illnesses as well (e.g., Mishara \& Ystgaard, 2006).

\section{Social and Emotional Learning}

The broadening of school mandates to focus on elements of development beyond simply academics is not a new phenomenon (e.g., Payton et al., 2000). However, efforts by groups such as the Collaborative for Academic, Social, and Emotional Learning (CASEL) in the United States have brought the infusion and targeted teaching of SEL into the research spotlight. While an analogous group does not yet exist in Canada, examples such as PREVNet (an extensive national network focused on relationshipfocused approaches to bullying prevention; PREVNet, 2014), and the Joint Consortium for School Health (JCSH, 2013) reflect an understanding of the need for research and knowledge mobilization related to SEL in schools. Many schools across North America and beyond have adopted whole-school (universal) approaches to mental health promotion that include a focus on SEL (e.g., Power, Cleary \& Fitzpatrick, 2008; Wells et al., 2003). Again, the focus is not simply on the development of individual skills by students, although this is a key aspect, but on the creation of environments, climates, and contexts where SEL is valued, promoted, and modeled.

Social-emotional learning has been defined as a process of acquiring knowledge, attitudes, and skills children need to "recognize and manage their emotions, demonstrate caring and concern for others, establish positive relationships, make responsible decisions, and handle challenging situations constructively" (CASEL, 2013 para. 1). The growing emphasis on SEL is based on the belief, as well as on research that suggests, that developing social-emotional skills will result in greater well-being and academic achievement; the reverse has also been demonstrated in that a lack of skills in these areas has been linked to a number of poor outcomes (e.g., Eisenberg, 2006; Guerra \& Bradshaw, 2008; Masten \& Coatsworth, 1998; Weissberg \& Greenberg, 1998). In terms of health promotion, an emphasis on developing SEL skills represents a positive, proactive approach that can be universally applied to all students. This will in theory prevent many mental health difficulties by providing students with skills they need to navigate relationships, difficult and stressful situations, and traumatic events. Students 
with these skills should be able to rely more strongly on their internal capacities and beliefs and be less subject to external changes and pressures (Bear \& Watkins, 2006). This theory is supported in part by research demonstrating that students low in emotional intelligence are more likely to intend to, or actually, smoke or drink alcohol—presumably because they are less able to resist peer pressure and navigate social situations where substances were offered or available (Austin, Saklofske, \& Egan, 2005; Trinidad \& Johnson, 2002; Trinidad, Unger, Chou, Azen, \& Johnson, 2004).

Varied approaches have been implemented in schools and other settings that focus on the development of SEL. Most of these include an emphasis on one or more of the five sets of cognitive, affective, and behavioural competencies outlined by the Collaborative for Academic, Social and Emotional Learning (CASEL, 2013): self-awareness, selfmanagement, social awareness, relationship skills, and responsible decision-making.

The most recent and comprehensive review of school-based programs focused on promoting students' social and emotional development was published in 2011 (Durlak, Weissberg, Dymnicki, Taylor, \& Schellinger, 2011). The authors were selective in their inclusion criteria, which focused on articles that: (a) emphasized the development of one or more SEL skills, (b) targeted students between the ages of 5 and 18 without any identified adjustment or learning problems, (c) included a control group, (d) reported sufficient information so that effect sizes could be calculated after the intervention or program was completed. For studies to be included, the programs described could not have primarily an academic focus and had to be offered universally (to all students) during regular school hours.

Some of the studies included in the review evaluated locally developed programs, and several included packaged, well-known programs such as the PATHS Curriculum (Greenberg \& Kusche, 1998), the Safe Dates program (Foshee et al., 1998), and the Positive Action program (Flay, Allred, \& Ordway, 2001). The PATHS Curriculum, as an example, consists of a series of grade-specific modules that include lessons that are taught two to three times per week for at least 20-30 minutes per day (PATHS, 2013). Modules contain approximately 50 lessons divided into a series of units. Lessons focus on giving students opportunities to practice identifying their feelings, understanding links between feelings and behaviours, techniques for improving self-control (e.g., three steps for calming down), and getting along with others.

Overall, students who participated in school-based, universal programs targeting specific SEL skills demonstrated more positive social behaviours, fewer conduct problems, less emotional distress and improved academic achievement compared to controls (Durlak et al., 2011). Effects were greatest for SEL skills and academic achievement. Programs were significantly more effective if they used active forms of learning, had a sequenced set of activities, and targeted specific SEL skills rather than more general positive development.

Many studies conducted since 2007 have evaluated the efficacy of various SELpromoting programs as well as a growing research base focused on mental health prevention and promotion more broadly (e.g., Brackett, Rivers, Reyes, \& Salovey, 2012; Conduct Problems Prevention Research Group, 2010). Alongside these, initiatives and policy frameworks aligned with or focused on mental health promotion and prevention in 
Canadian schools, including an emphasis on SEL, continue to emerge and develop. Few of these have been the subjects of evaluation studies (Guyn Cooper Research Associates, 2013), but many include elements found in related research to be key to effective programming, at both classroom and leadership levels.

\section{Social and Emotional Learning in Canadian Schools}

Although the bulk of the research in the SEL field has been carried out in the United States, a focus on SEL is evident at a number of levels in Canada. Recently, a report was released that included a review of literature as well as interviews with key informants from across Canada including academics, policy advisors, program providers, and funders on the topic of SEL in the education system (Guyn Cooper Research Associates, 2013). Results confirmed the "dizzying array of programs and frameworks" (p. 5) as well as the lack of evidence supporting their efficacy. The participants also highlighted a number of factors that they believed would influence the future of SEL in Canadian schools. These included recognition of SEL by the Mental Health Commission of Canada, the focus on SEL competencies by many provincial ministries, a movement towards whole-school and cross-sectoral approaches, and a growing need for SEL skills in the labour force. Many barriers to the advancement of the SEL field were also identified including insufficient knowledge exchange across the country, an overwhelming number of programs for educators to choose from, a lack of alignment between SEL and achievement within provincial education ministries, and a lack of teacher training.

A second report was also released in 2013, authored by Morrison and Peterson of the JCSH and focused on the promotion of positive mental health practices in schools. The JCSH consists of government representatives from health and education sectors in all provinces and territories except Québec. The consortium does not conduct research or deliver programs but "works as a catalyst to encourage collaboration and cooperation in support of comprehensive school health" (2013, p. 1). Its areas of focus include knowledge development, leadership, and capacity building. Interestingly, although the participants in the Guyn Cooper study noted fragmentation across the country as a barrier to advancing the SEL field, the JCSH was not mentioned.

In the report by Morrison and Peterson (2013), research in the area of mental health promotion in schools was reviewed and interviews were conducted with 17 key informants including school administrators, teachers, school counsellors, school psychologists, social workers, and student services personnel. Myriad suggestions were made by participants with respect to creating environments for students that promoted comprehensive school health (CSH), with mental health listed as a key element. Among other factors, participants highlighted the role of SEL in positive mental health as well as the need for targeted instruction in related skills. A number of practice statements emerged from the report, including the need to "enhance understanding among school health stakeholders and the wider community regarding positive mental health perspectives and practices, and their relationship to students' social-emotional functioning and academic development" (p. 71). This statement aligns with research literature as well as with the perspectives captured in the Guyn Cooper report (2013). 
While a focus on SEL is evident in comprehensive school health frameworks of JCSH and others (Alberta Health Services, Population and Public Health, 2012; University of Ottawa, 2014), SEL literature is rarely situated within CSH. Both SEL and CSH include a focus on mental health promotion, but research and practice areas do not always intersect, and varied language and terminology is used. The issue of varied terminology use, as well as parallel rather than collaborative research agendas, can also present barriers in the ongoing growth and development of research and practice in mental health promotion and SEL in particular.

As discussed in the Guyn Cooper (2013) and Morrison and Peterson (2013) reports, SEL is being addressed in a number of ways in Canadian schools; they are included as learning outcomes in the curricula of many provinces and territories, as well as being the subject of many policy statements and initiatives. Across these provinces, the approach to addressing these learning outcomes and implementing the initiatives varies a great deal. While some schools and systems incorporate the principles using less formal, and/or locally developed programs, others have turned to structured programs and direct teaching approaches to support the SEL of their students.

Although a comprehensive survey of SEL in Canadian schools is beyond the scope of this paper, the following section provides examples of ways in which the components of SEL as defined by CASEL are being addressed in schools in provinces and territories across Canada. These components include: self-management, self-awareness, responsible decision-making, social awareness, and relationship skills (CASEL, 2013). SEL expectations are often outlined in the overall learning goals, are a major component of Early Learning and Kindergarten programs, and/or are embedded in subject areas such as Health and Physical Education and Social Studies. SEL is also infused into the classroom in less explicit ways, such as through inclusion as topics of discussion and through approaches to classroom management and teaching. As well, each province has specific initiatives and polices related to healthy living, which include at least some of the components of SEL. These include policies related to issues such as character education and anti-bullying as well as ones directed specifically at the promotion of mental health and SEL.

\section{SEL in Overall Learning Goals}

As stated, learning goals that address components of SEL are included in education curricula of many provinces. While they have often been part of the curricula in some form for many years, they have not always been given the same time or attention as the more academic learning expectations. Recognizing that many students seem to lack these skills, a number of provinces have revised their curricula to give SEL-related expectations more prominence. SEL-type expectations are included explicitly in some subject areas, but are also included as overall goals and/or qualities that facilitate learning.

Examples of overall learning expectations include Saskatchewan's Goals of Education outlined in 1985 (Saskatchewan Ministry of Education, 1985). The goals included basic academic skills in reading, writing, mathematics, and problem solving as well as more general goals and aspirations including lifelong learning, decision making 
with regards to career, and coping with change over time. Other goals with a focus on social and emotional development were also included such as understanding and accepting individual differences in terms of race, religion and personal attributes, developing a positive self-image, making positive and healthy lifestyle choices, and being a responsible member of society. These goals were expanded upon and described as Common Essential Learnings (Saskatchewan Ministry of Education, 1998) with SEL being included as Personal and Social Development (Saskatchewan Ministry of Education, 2008). Revised again in 2010, Saskatchewan's CELs have been redefined as Cross-Curricular Competencies with SEL elements included as Developing Identity and Interdependence (2010), which connect to many of the components of SEL as defined by CASEL (2013). For example, students are expected to develop social- and self-awareness as they learn to "understand, value, and care for oneself ....and others" (Saskatchewan Ministry of Education, 2010, p. 1).

Similarly, Ontario's curriculum includes a focus on specific learning strategies. While the descriptions of the strategies make clear connections to academic success, there are also connections to social-emotional skills and well-being. Included as Personal and Social Development expectations in past versions of the curriculum (Ontario Ministry of Education, 1995), they are currently called Learning Skills and Work Habits and include: responsibility, organization, independent work, collaboration, initiative, and self-regulation. Rather than drawing on support from SEL research, however, Ontario has identified a list of proficiencies that are key to employability upon which the learning skills are based. They have also linked the skills to their Character Education initiative (Ontario Ministry of Education, 2010a). No mention is made of the connections between the learning skills and social-emotional competencies or mental health promotion. As well, while teachers are expected to assess student performance in these areas, there is little attention paid to the ways in which teachers might instruct or facilitate development of these complex skills. Teachers may not have the training or resources available to teach and implement SEL competencies (Guyn Cooper Research Associates, 2013).

Examples of a similar focus on learning strategies or learning expectations in other provinces include: Alberta's Guide to Education: ECS to Grade 12, where they are included under the Student Learning Outcomes of a basic education (Alberta Education, 2012). In the Atlantic provinces (New Brunswick, Newfoundland and Labrador, Nova Scotia, and Prince Edward Island) they are described as the Atlantic Canada Education Foundation for Essential Graduation Learnings (Atlantic Provinces Education Foundation, n.d.). Expectations considered essential for graduation include, for example, citizenship, with elements that relate to social-awareness and personal development with competencies that relate to self-awareness. While terminology may have changed, it is clear that the concepts included within the more recent SEL framework have existed within the expectations of various Ministries of Education for some time. Furthermore, as these expectations are housed within curriculum, there is a requirement for schools to ensure that students are assessed in these areas. It is not always evident, however, how teachers can provide sufficient and effective instruction and guidance to ensure that each student masters skills such as "builds healthy peer-to peer relationships" or "assesses and reflects critically on own strengths, needs, and interests" as, for example, outlined by the Ontario Ministry of Education (2010a, p. 11). 


\section{SEL Explicit in Early Learning Curriculum}

As well as appearing in the overall learning goals of curriculum, SEL competencies are often explicitly included other areas of the curriculum. SEL expectations have traditionally been evident in early learning/kindergarten programs, and as stated earlier, this is often a key focus for teachers and early childhood educators in the early years of school (Hemmeter et al., 2006; Rimm-Kaufman et al., 2000).

The kindergarten curriculum in Alberta contains strands that outline expectations for Personal and Social Responsibility as well as Citizenship and Identity. Expectations within these strands include developing social skills, the ability to express emotions in positive ways, independence, and positive relationships, as well as a sense of identity, self-esteem, and belonging (Alberta Education, 2008). Similar to the Alberta program, separate personal and social development strands are included in the draft version of the Full-day Early Learning Kindergarten Program in Ontario (Ontario Ministry of Education, 2010b). Learning outcomes include the development of social skills, problemsolving skills in social contexts, a sense of identity, and a positive self-image, as well as independence, self-regulation, a willingness to take responsibility in learning, and other activities that echo the elements of SEL described. Similar expectations can be seen in the kindergarten curricula of many other provinces (e.g., British Columbia Ministry of Education, 2010a; Northwest Territories Education, Culture, and Employment, 2012; Prince Edward Island Department of Education and Early Childhood Development, 2008)

\section{SEL Explicit in Health Curriculum}

A focus on SEL in terms of positive relationships and constructive lifestyle choices has often been included in the Health section of provincial curricula. In Nova Scotia the overall expectations for health include demonstrating positive self-identity, making informed decisions to enhance health, and developing effective communication and interpersonal skills (Nova Scotia Department of Education, 2012). Similar expectations are found in Ontario's curriculum (Ontario Ministry of Education, 2010c). In Alberta, there is a separate segment of the curriculum called Wellness, which includes the physical sense but also emotional, intellectual, social, and spiritual wellness (Alberta Education, 2009). The Health and Career Education sections of the curriculum in British Columbia present another example of SEL embedded in the curriculum. A recent brochure promoting these specific expectations is another example of the new prominence of SEL (British Columbia Ministry of Education, 2010b). The focus of the expectations in British Columbia is on the development of healthy relationship skills, as well as more general social and emotional development and well-being, which relate directly to the core competencies of the SEL framework (CASEL, 2013). Again, similar expectations can be found in the Health curricula of other provinces (e.g., Department of Education Newfoundland \& Labrador, 2010; Gouvernement du Québec Ministère de l'Éducation, 2013; Manitoba Education, 2001; New Brunswick Department of Education and Early Childhood Development, 2001).

While SEL competencies are most often included in Health curricula, components of SEL involving identity (self-awareness) and citizenship (relationship skills) also appear 
in the expectations included in the Social Studies curriculum of most provinces. The connections to SEL are more evident in the early grades. For example, in the Identity, Society, and Culture strand of the Social Studies curriculum in British Columbia, the Grade 2 expectations include "identify factors that influence who they are" (selfawareness) while the Grade 5 expectations focus more on events in the history of British Columbia and Canada (British Columbia Ministry of Education, 2006, p. 42).

The curriculum of the Northwest Territories provides an example of SEL learning expectations as part of overall learning goals, which are also explicitly integrated into other subject areas. Based on the traditional language, culture, and world view of the Dene people, the Dene Kede curriculum (Northwest Territories Education, Culture, and Employment, 1993) includes topics and values related to the Spiritual World, the Land, the Self, and the People. Similarly, the Inuuqatigiit (Northwest Territories Education, Culture, and Employment, 1996) curriculum encompasses Inuit history, traditions, knowledge, values, and beliefs. The central competencies of SEL (CASEL, 2013), such as self- and social-awareness, are evident in core values such as "Respect for ourselves, others and the environment. From this important value will follow others, such as pride, self-esteem, independence and a willingness to learn, contribute, share and have a welcoming nature" (Northwest Territories Education, Culture, and Employment, 1996). Both the Dene Kede and the Inuuqatigiit provide the basis for the Northern Studies part of the curriculum representing the topics and ideas covered in History, Geography, and Social Studies of other provinces which are intended to "contribute to students' sense of identity and connectedness to narratives which are local, territorial, national and global" (Northwest Territories Education, Culture, and Employment, 2013, para. 1). This strong integration of school and culture demonstrates the view that a family, community, and the environment are essential components that facilitate development of social-emotional well-being.

Opportunities to address SEL occur more indirectly in other areas of the curriculum; for example, interpersonal skills such as effective communication and active listening are often included in language expectations. Also, topics involved with health promotion as well as mental health - such as relationships, lifestyle choices, and issues such as bullying and racism - are often incorporated as topics in Language and Social Studies. While this is done as part of an integrated approach to teaching by many teachers, it can also be supported by the school system through the choice of resources. For example, the Nelson Literacy program contains cross-curricular connection to Health and Social Studies expectations and topics such as character education (MacKenzie, 2007).

\section{SEL Initiatives}

In addition to addressing SEL within the curriculum learning expectations, many school systems have introduced initiatives and/or policy statements that address SEL objectives. Although the names and elements vary, each of the provinces has embraced a comprehensive view of health where the integration of physical, social, and emotional well-being are seen as important aspects of learning and school life. A Comprehensive School Health $(\mathrm{CSH})$ framework or approach includes elements of SEL but expands more broadly to include multiple indicators of health and well-being. This approach 
responds to concerns identified in the literature that the multitude of discreet initiatives, programs, and curricula focusing on SEL and mental health lack a cohesive framework and run the risk of being perceived as unsustainable in the long term (Greenberg et al., 2001; Guyn Cooper Research Associates, 2013; Whitley, 2010). The JCSH also states "in recent years, school health proponents, program planners, and policy-makers have recognized the need for a more systematic and policy-oriented approach to comprehensive school health" (2013, para. 1).

At a national level, the JCSH has as one of its goals the facilitation of "a cohesive pan-Canadian approach to advancing comprehensive school health and enhancing alignment between health and education across multiple sectors" (2013, para. 4 ). The model of CSH adopted by JCSH contains four overlapping pillars: social and physical environment, teaching and learning, healthy school policy, and partnerships and services. These elements appear in the CSH frameworks adopted by many provinces and territories (e.g., Manitoba Education, 2012; Newfoundland \& Labrador, 2006; Prince Edward Island Department of Education and Early Childhood Development, 2014).

Within the various CSH frameworks, initiatives may focus on specific issues such as bullying, racism, drugs, and alcohol but also maintain more general objectives such as promoting positive relationships and healthy life choices. For example, Ontario's Accepting Schools Act (Legislative Assembly of Ontario, 2012) is aimed at bullying reduction; however, its goal is also to "support students who want to promote understanding and respect for all" (Ontario Ministry of Education, 2014, para. 3). The Act is supported through other initiatives such as the Safe Schools Strategy (Ontario Ministry of Education, 2014) and Character Development (Ontario Ministry of Education, 2008) and through resources that promote a positive school climate. Examples of similar policies in other provinces include Caring and Respectful Schools in Saskatchewan (Saskatchewan Learning, 2004) and Safe, Caring, and Orderly Schools in British Columbia (British Columbia Ministry of Education, 2008).

In a number of provinces SEL components have been highlighted and made more explicit within the CSH framework. For example, Yukon's healthy living website (Yukon Education, 2014) includes an explanation of SEL based on the components described by CASEL and explains the importance of SEL and emotional literacy for both students and educators. There is also a description of the MindUP program (The Hawn Foundation, 2014), which is used in the schools and focuses on self-awareness and self-regulation. Similarly, in Québec, the Healthy Schools document makes specific reference to selfesteem and social competence as key components of their overall approach (Gouvernement du Québec Ministère de l'Éducation, 2005). The Healthy Schools BC program (DASH BC, 2013) includes a focus on mental health, specifically on healthy relationships; however, participation in the program is on a voluntary basis rather than mandated by the province. Many provinces, including British Columbia, New Brunswick, Prince Edward Island, and Manitoba also make reference to the Positive Mental Health Toolkit, a resource created by JCSH intended to "promote positive mental health perspectives and practices in the school context" (Joint Consortium of School Health, 2014, p.5). As described in the document, positive mental health is a combination of many components including SEL. 
At present the elements of CSH, including those specifically focused on SEL, are addressed by school and board staff in a variety of ways. Many rely on locally developed programs such as acknowledging a positive character trait every month and/or behaviour management strategies that reward good behaviour, while others have turned to more formal, structured programs such as the PATHS or MindUPTM programs. Research findings have demonstrated that programs that are implemented school- and/or districtwide and delivered by teachers or other school staff are more effective than those that are delivered in more limited ways or by non-school personnel (Durlak et al., 2011; Han \& Weiss, 2005).

In terms of effectiveness, programs and interventions that involve whole-school approaches and include staff, parents, families, and communities have been found to be more effective than those that target individuals (Wells et al., 2003). This finding is reflected in many of the CSH approaches. For example, the Alberta Coalition for Healthy School Communities (2011) has adopted a "whole' school approach...where students, teachers, parents, school staff, community groups, agencies, and institutions work together on key priorities for improving health and educational attainment" (para. 2). Similarly, in Manitoba, the Healthy Schools program is based on the "belief that health is important and that schools are uniquely positioned to influence healthy child, youth, and family development" and extends the focus on wellness of students to include their families, school staff, and school communities (Manitoba Education, 2014). The connection to family and community also appears in Québec's Healthy Living document. It states, "it is...critical that promotion and prevention measures be harmonized with the actual situation of the school" (Gouvernement du Québec Ministère de l'Éducation, 2005, p. 30) and places the student at the centre being equally influenced by school, family and community.

\section{Discussion}

Mental health issues continue to present barriers for Canadian children, in terms of both psychological and academic outcomes. Growing numbers of students are placed at risk as a result. A mental health promotion approach suggests that students can develop a number of skills and competencies, namely those related to SEL, which can reduce their chance of developing mental health difficulties. Furthermore, students who have developed SEL competencies can apply them to their school work and therefore experience greater academic success.

In Canada, SEL approaches have been integrated in school systems in a variety of ways for many years. Across the provinces and territories, this is most evident within the overall learning goals and Health curricula as well as in the curricula for early learning and kindergarten programs. The inclusion of SEL competencies reflects an understanding of their benefits as well as a focus on promotion and prevention. A recent emphasis in research literature, knowledge mobilization efforts spearheaded by groups such as CASEL, and a cross-ministerial and national focus on mental health issues among children and youth (Arboleda-Flórez, 2005; Leitch, 2007; Roberts, Stuart \& Lam, 2008; Waddell \& Shepherd, 2002) has led to renewed interest in SEL. In some cases this has led to revising of the curriculum, and a strengthening of the focus on health and well- 
being across subjects and across communities. In other cases concerns over mental health and specific issues such as bullying have resulted in the creation of initiatives, policies, and programs related to SEL. However, in a recent report (Guyn Cooper Research Associates, 2013), Canadian experts in the area of SEL point to the wide range of programs, initiatives, and frameworks, most without evidence of efficacy, as a barrier to advancement in the field.

While the renewed interest in SEL is important, there is a tendency to view new school-based initiatives such as those described above as temporary or as add-ons (Adelman \& Taylor, 2007. A number of elements are required for successful and lasting implementation of any initiative, including a shared vision, organizational support, and strong leadership at both the school and district level (for a review, see Whitley, 2010). While organizational support is evident in the creation of the frameworks and initiatives, inclusion of SEL in the curriculum in a more prominent position places more value on these competencies. As expectations to be assessed, teachers and school staff are responsible for ensuring that students are given the opportunity to develop skills in these areas. However, teachers may not have sufficient training or resources available to teach and implement SEL competencies (Guyn Cooper Research Associates, 2013).

It is also key that the environmental aspects of mental health promotion and SEL approaches be considered. There are multiple influences that can impact the well-being of students, and thus efforts to improve this should be equally multi-faceted (e.g., Durlak \& Wells, 1997). Research has identified key elements of effective mental health-promotion programs, which include: whole-school approaches that involved students, staff, families and community; a focus on environmental changes throughout the school; and long-term sustainability (Stewart-Brown et al., 2004; Weare \& Markham, 2005; Weare \& Nind, 2011; Wells et al., 2003). In fact, teachers participating in an evaluation of Alberta's CSH initiative described how a shift in school culture is necessary in order for the approach to be effective (Storey, Spitters, Cunningham, Schwartz, \& Veugelers, 2011). A shared school, board, and provincial focus within an integrated framework like CSH has the potential to facilitate a sustainable focus on developing environments that support the social, emotional, and academic well-being of students. Like many other policies and initiatives in the area, however, the actual implementation of the elements of CSH frameworks vary widely and require evaluation in order to determine efficacy and sustainability.

\section{Conclusion}

In this paper, we have outlined one approach to addressing the issue of the growing number of students being identified with mental health difficulties and illness in Canada. This involves moving from a deficit-based focus in which we wait to intervene when students have already developed depression or anxiety and are officially at risk for academic failure, to one where we begin in the early grades to promote healthparticularly mental health - and aim to prevent the development or worsening of mental health and academic issues. This prevention approach is evident to some degree in policy, curriculum, initiatives, or frameworks emerging from education and/or health ministries 
of every province and territory in Canada. Whether or not these are effective is not yet known.

Ongoing research in this area is crucial, particularly within the complex, everchanging context of educational settings. For example, many programs based on mental health promotion and SEL have shown short-term efficacy in terms of facilitating social and emotional skill development and improving school behaviour and academic achievement among elementary-aged students. However, whether these changes are truly effective in improving long-term mental health and academic outcomes of students, and whether they remove the "at risk" label that many students gain by virtue of their mental health difficulties, has not yet been determined. As well, provincial ministries and school boards have developed a wealth of initiatives locally, which may or may not include the evidence-based practices identified in research. In an effort to avoid mental health promotion and prevention programs going the way of many other transient initiatives, it is necessary to have them embedded in "regular" school practices but also to have ongoing evaluations of process and outcome that assess efficacy with respect to mental health outcomes, but, given the priorities of all education Ministries, academic success as well.

\section{References}

Adelman, H. S., \& Taylor, L. (2007). Systemic change for school improvement. Journal of Educational and Psychological Consultation, 17(1), 55-77.

Alberta Coalition for Healthy School Communities. (2011). Mission/Vision. Retrieved from http://www.achsc.org/vision_mission.htm

Alberta Education. (2008). Kindergarten program statement. Edmonton, AB: Author. Retrieved from $\mathrm{http}: / /$ education.alberta.ca/department/publications.aspx

Alberta Education. (2009). A framework for wellness education: Kindergarten to Grade 12. Edmonton, AB: Author. Retrieved from http://education.alberta.ca/teachers/program/pe.aspx

Alberta Education. (2012). Guide to education: ECS to Grade 12. Edmonton, AB: Author. Retrieved from http://education.alberta.ca/department/publications.aspx

Alberta Health Services, Population and Public Health. (2012). AHS Framework for the comprehensive school health approach. Calgary, AB: Author. Retrieved from http://www.albertahealthservices.ca/SchoolsTeachers/if-sch-sch-ahs-framework.pdf

Arboleda-Flórez, J. (2005). The epidemiology of mental illness in Canada. Canadian Public Policy, 31(s1), 13-16.

Atlantic Provinces Education Foundation (n.d.). The Atlantic Canada framework for essential graduation learnings in schools. http://www.ednet.ns.ca/files/reports lessential_grad_learnings.pdf

Austin, E. J., Saklofske, D. H., \& Egan, V. (2005). Personality, well being and health correlates of trait emotional intelligence. Personality and Individual Differences, 38, 547-558.

Bear, G. G., \& Watkins, J. M. (2006). Developing self-discipline. In G. G. Bear \& K. M. Minke (Eds.), Children's needs III: Development, prevention, and intervention ( $\mathrm{pp}$. 29-44). Bethesda, MD: National Association of School Psychologists. 
Brackett, M. A., Rivers, S. E., Reyes, M. R., \& Salovey, P. (2012). Enhancing academic performance and social and emotional competence with the RULER feeling words curriculum. Learning and Individual Differences, 22, 218-224.

British Columbia Ministry of Education. (2006). Social studies K to 7: Integrated resources package. Victoria, BC: Author. Retrieved from http://www.bced.gov.bc.ca/irp/course.php ?lang $=$ en\&subject $=$ Social_Studies\&course $=$ Social_Studies_K_to_7\&year $=2006$

British Columbia Ministry of Education. (2008). Safe, caring, and orderly schools: A guide. Victoria, BC: Author. Retrieved from http://www.bced.gov.bc.ca/sco

British Columbia Ministry of Education. (2010a). Kindergarten: Curriculum package. Retrieved from http://www2.gov.bc.ca/gov/topic.page?id=AC8D9B60C99E4F5987D5549EB8FCB1B6\&title $=$ Curriculum

British Columbia Ministry of Education. (2010b). Your role in helping children and youth develop healthy relationship skills. Victoria, BC: Author. Retrieved from http://www.bced.gov.bc.ca /sco/relationship.pdf

Brown, L. (2011). Mental health top issue facing schools, coalition says. Toronto Star, Wednesday, June 1. Retrieved from http://www.thestar.com/news/canada/article/1001024--mental-healthtop-issue-facing-schools-coalition-says

Cameron, R., \& Kerner, J. (2013). Health promotion approaches to reducing cancer incidence. In A. B. Miller (Ed.), Epidemiologic studies in cancer prevention and screening (pp. 3-19). New York, NY: Springer Science.

CASEL. (2013). What is social emotional learning? Retrieved from http://www.casel.org/social-andemotional-learning/

Chisholm, K., Patterson, P., Torgerson, C., Turner, E., \& Birchwood, M. (2012). A randomised controlled feasibility trial for an educational school-based mental health intervention: study protocol. BMC Psychiatry, 12(23), 1-7.

Conduct Problems Prevention Research Group. (2010). The effects of a multi-year randomized clinical trial of a universal social-emotional learning program: The role of student and school characteristics. Journal of Consulting and Clinical Psychology, 78(2), 156-168.

DASH BC. (2013). Healthy Schools BC. Retrieved from http://www.healthyschoolsbc.ca/

DeJong, W., \& Langford, L. M. (2002). A typology for campus-based alcohol prevention: Moving toward environmental management strategies. Journal of Studies on Alcohol and Drugs, Supplement No. 14, 140-147.

Department of Education Newfoundland and Labrador. (2010). Health: Grade 1. Retrieved from http://www.ed.gov.nl.ca/edu/k12/curriculum/guides/health/index.html

Durlak, J. A., Weissberg, R. P., Dymnicki, A. B., Taylor, R. D., \& Schellinger, K. B. (2011). The impact of enhancing students' social and emotional learning: A meta-analysis of school-based universal interventions. Child Development, 82(1), 405-432.

Durlak, J. A., \& Wells, A. M. (1997). Primary prevention mental health programs for children and adolescents: A meta-analytic review. American Journal of Community Psychology, 25, 115152.

Eisenberg, N. (Ed.). (2006). Social, emotional, and personality development. In W. Damon \& R. M. Lerner (Series eds.), Handbook of child psychology (6th ed., Vol. 3). New York: Wiley.

Elias, M. J. (2009). Social-emotional and character development and academics as a dual focus of educational policy. Educational Policy, 23(6), 831-846. 
Fergusson, D. M., \& Woodward, L. J. (2002). Mental health, educational, and social role outcomes of adolescents with depression. Archives of General Psychiatry, 59(3), 225-231.

Flay, B. R., Allred, C. G., \& Ordway, N. (2001). Effects of the positive action program on achievement and discipline: Two matched-control comparisons. Prevention Science, 2, 7189.

Foshee, V. A., Bauman, K. E., Arriaga, X. B., Helms, R. W., Koch, G. G., \& Linder, G. F. (1998). An evaluation of Safe Dates, an adolescent dating and violence prevention program. American Journal of Public Health, 88, 45-50.

Gouvernement du Québec Ministère de l'Éducation. (2005). Healthy schools: Guide for the education community and its partners. Retrieved from http://www.mels.gouv.qc.ca/fileadmin /site_web/documents/publications/EPEPS/Formation_jeunes/Adaptation_scolaire/GuideForT heĒucCommunityPartners_HealthySchools_19-7062a.pdf

Gouvernement du Québec Ministère de l'Éducation. (2013). Progression primaire: Éducation physique et à la santé. Retrieved from http://www1.mels.gouv.qc.ca/progressionPrimaire /educationPhysique/index.asp?page=adopterModeVie_connaissance_habitudeVie

Greenberg, M. T., Domitrovich, C., \& Bumbarger, B. (2001). The prevention of mental disorders in school-aged children: Current state of the field. Prevention and Treatment, 4, 1-59.

Greenberg, M. T., \& Kusche, C. A. (1998). Promoting alternative thinking strategies. Boulder, CO: Institute of Behavioral Sciences, University of Colorado.

Guerra, N. G., \& Bradshaw, C. P. (2008). Linking the prevention of problem behaviors and positive youth development: Core competencies for positive youth development and risk prevention. New Directions for Child and Adolescent Development, 122, 1-17.

Guyn Cooper Research Associates. (2013). Issue brief: Social and emotional learning in Canada. Retrieved from http://www.maxbell.org/sites/default/files/SELIssueBrief.pdf

Han, S. S., \& Weiss, B. (2005). Sustainability of teacher implementation of school-based mental health programs. Journal of Abnormal Child Psychology, 33(6), 665-679.

Hemmeter, M. L., Ostrosky, M., \& Fox, L. (2006). Social and emotional foundations for early learning: A conceptual model for intervention. School Psychology Review, 35, 583-601.

Howes, C., Burchinal, M., Pianta, R., Bryant, D., Early, D., Clifford, R., \& Barbarin, O. (2008). Ready to learn? Children's pre-academic achievement in pre-kindergarten programs. Early Childhood Research Quarterly, 23, 27-50.

Hoyt, H. H., \& Broom, B. L. (2002). School-based teen pregnancy prevention programs: A review of the literature. Journal of School Nursing, 19(1), 11-17.

Joint Consortium for School Health. (2013). About the consortium. Retrieved from http://www.jcshcces.ca/index.php/about-the-consortium

Joint Consortium for School Health. (2014). Positive mental health toolkit. Retrieved from http://www.jcshpositivementalhealthtoolkit.com/

Kickbusch, I. (2003). The contribution of the world health organization to a new public health and health promotion. American Journal of Public Health, 93(3), 383-388.

Legislative Assembly of Ontario. (2012). Accepting schools act. Toronto, ON: Author. Retrieved from http://ontla.on.ca/web/bills/bills_detail.do?locale=en\&BillID $=2549$

Leitch, K. K. (2007). Reaching for the top: A report by the advisor on healthy children and youth. Health Canada (Catalogue H21-296/2007E). Ottawa, ON: Minister of Public Works and Government Services Canada.

MacKenzie, J. (2007). Nelson literacy 4: Student book 4a. Toronto, ON: Nelson Education. 
Manitoba Education. (2001). Manitoba physical education/health education curriculum overview. Retrieved from http://www.edu.gov.mb.ca/k12/cur/physhlth/c_overview.html

Manitoba Education. (2012). What is comprehensive school health? Retrieved from http://www.gov.mb.ca/healthyschools/csh.html - .U3tekijtLmU

Manitoba Education. (2014). Healthy schools. Retrieved from http://www.gov.mb.ca/healthyschools /about.html - .U3ujayjtLmU

Masten, A. S., \& Coatsworth, J. D. (1998). The development of competence in favorable and unfavorable environments: Lessons from research on successful children. American Psychologist, 53, 205-220.

McLeroy, K. R., Bibeau, D., Steckler, A., \& Glanz, K. (1988). An ecological perspective on health promotion programs. Health Education Quarterly, 15(4), 351-377.

Meldrum, L., Venn, D., \& Kutcher, S. (2009). Mental health in schools: How teachers have the power to make a difference. Health \& Learning Magazine, 8, 3-5.

Minkler, M. (1989). Health education, health promotion and the open society: An historical perspective. Health Education Behavior, 16(1), 17-30.

Mishara, B. L., \& Ystgaard, M. (2006). Effectiveness of a mental health promotion program to improve coping skills in young children: "Zippy's Friends". Early Childhood Research Quarterly, 21(1),110-123.

Morrison, W., \& Peterson, P. (2013). Schools as a setting for promoting positive mental health: Better practices and perspectives (2nd ed.). Summerside, PEI: Joint Consortium for School Health. Retrieved from http://www.jcsh-cces.ca/upload/JCSH\%20Best\%20Practice_Eng_Jan21.pdf

New Brunswick Department of Education and Early Childhood Developmemt. (2001). Health education curriculum kindergarten to Grade 5. Retrieved from http://www.gnb.ca /0000/anglophone-e.asp

Newfoundland and Labrador. (2006). Living healthy, healthy schools. Retrieved from http://www.livinghealthyschools.com/livinghealth_overview.html

Northwest Territories Education, Culture, and Employment. (1993). Dene Kede: Education, a Dene perspective, grades $K-6$. Fort Simpson, NT: Author. Retrieved from http://www.ece.gov.nt.ca /early-childhood-and-school-services/school-services/curriculum-k-12

Northwest Territories Education, Culture, and Employment. (1996). Inuuqatigiit: The curriculum from the Inuit perspective, $K-12$. Fort Simpson, NT: Author. Retrieved http://www.ece.gov.nt.ca /early-childhood-and-school-services/school-services/curriculum-k-12

Northwest Territories Education, Culture, and Employment. (2012). Integrated Kindergarten curriculum: A holistic approach to children's learning. Fort Simpson, NT: Author. Retrieved from http://www.ece.gov.nt.ca/early-childhood-and-school-services/school-services/earlylearning-kindergarten

Northwest Territories Education, Culture, and Employment. (2013). Social studies and northern studies. Fort Simpson, NT: Author. Retrieved from http://www.ece.gov.nt.ca/earlychildhood-and-school-services/school-services/curriculum-k-12/social-studies-and-northern

Nova Scotia Department of Education. (2012). Learning outcomes framework: Grades primary-6 . Halifax, NS: Author. Retrieved from http://www.ednet.ns.ca/psp-lof.shtml

Ontario Ministry of Education. (1995). The common curriculum: Policies and outcomes, grades 1-9, 1995. Toronto, ON: Queen's Printer for Ontario.

Ontario Ministry of Education (2008). Finding common ground: Character development in Ontario schools, $K-12$. Toronto, ON: Author. http://www.edu.gov.on.ca 
Ontario Ministry of Education. (2010a). Growing success: Assessment, evaluation and reporting in Ontario schools. Toronto, ON: Queen's Printer for Ontario.

Ontario Ministry of Education. (2010b). Full-day early learning-kindergarten program: Draft version. Toronto, ON: Queen's Printer for Ontario.

Ontario Ministry of Education. (2010c). Ontario curriculum grades 1-8: Health and physical education (Revised interim ed.). Toronto, ON: Queen's Printer for Ontario.

Ontario Ministry of Education. (2014). Safe and accepting schools. Toronto, ON: Author. Retrieved from http://www.edu.gov.on.ca/eng/teachers/safeschools.html

PATHS. (2013). PATHS ${ }^{\circledR}$ Program from Channing Bete Company [Web page]. Retrieved from http://www.channing-bete.com/prevention-programs/paths/paths.html

Payton, J. W., Wardlaw, D. M., Graczyk, P. A., Bloodworth, M. R., Tompsett, C. J., \& Weissberg, R. P. (2000). Social and emotional learning: A framework for promoting mental health and reducing risk behaviors in children and youth. Journal of School Health, 70(5), 179-185.

Payton, J. W., Weissberg, R. P., Durlak, J. A., Dymnicki, A. B., Taylor, R. D., Schellinger, K. B., \& Pachan, M. (2008). The positive impact of social and emotional learning for kindergarten to eighth-grade students: Findings from three scientific reviews. Chicago, IL: Collaborative for Academic, Social, and Emotional Learning.

Power, M., Cleary, D., \& Fitzpatrick, C. (2008). Mental health promotion in Irish school: A selective review. Advances in School Mental Health Promotion, 1(1), 5-15.

PREVNet. (2014). About: Promoting relationships and eliminating violence network [Web page]. Retrieved from http://www.prevnet.ca/about

Prince Edward Island Department of Education and Early Childhood Development. (2008). Kindergarten integrated curriculum document. Charlottetown, PEI: Author. http://www.gov.pe.ca/eecd/index.php3?number=1027167\&lang=E

Prince Edward Island Department of Education and Early Childhood Development. (2014). What is comprehensive school health? http://www.gov.pe.ca/healthyschoolcommunities /index.php?number $=1046768$ \&lang $=\mathrm{E}$

Public Health Agency of Canada. (2012) Frequently asked questions: What is mental health promotion? Retrieved from http://www.phac-aspc.gc.ca/mh-sm/mhp-psm/faq-eng.php

Ranz-Smith, D. (2007). Teacher perception of play: In leaving no child behind are teachers leaving childhood behind? Early Education and Development, 18(2), 271-303.

Rimm-Kaufman, S. E., Pianta, R. C., \& Cox, M. J. (2000). Teachers' judgements of problems in the transition to kindergarten. Early Childhood Research Quarterly, 15(2), 147-166.

Roberts, N., Stuart, H., \& Lam, M. (2008). High school mental health survey: Assessment of a mental health screen. Canadian Journal of Psychiatry, 53(5), 314-322.

Saskatchewan Learning. (2004). Caring and respectful schools: Towards School ${ }^{\text {LLUS }}$ : Ensuring student well-being and educational success. Regina, SK: Author. Retrieved from http://www.education.gov.sk.ca/caring-and-Respectful-schools

Saskatchewan Ministry of Education. (1985). Goals of education. Regina, SK: Author. Retrieved from http://curriculum.gov.sk.ca/?lang=en

Saskatchewan Ministry of Education. (1998). Objectives for the common essential learnings (C.E.L.s). Regina, SK: Author. Retrieved from http://www.education.gov.sk.ca/Objectives-CEL

Saskatchewan Ministry of Education. (2008). Renewed objectives for the common essential learnings of critical and creative thinking (CCT) and personal and social development 
$(P S D)$. Regina, SK: Author. Retrieved from http://www.education.gov.sk.ca/ObjectivesCEL

Saskatchewan Ministry of Education. (2010). Cross-curricular competencies. Regina, SK: Author. from http://curriculum.gov.sk.ca/?lang=en

Schonert-Reichl, K. A., \& Stewart Lawlor, M. (2010). The effects of a mindfulness-based education program on pre- and early adolescents' well-being and social and emotional competence. Mindfulness, 1, 137-151.

Snyder, F., Flay, B., Vuchinich, S., Acock, A., Washburn, I., Beets, M., \& Li, K. (2009). Impact of a social-emotional and character development program on school-level indicators of academic achievement, absenteeism, and disciplinary outcomes: A matched-pair, cluster-randomized, controlled trial. Journal of Research on Educational Effectiveness, 3(1), 26-55.

Stewart-Brown, S., Patterson, J., Mockford, C., Barlow, J., \& Pyper, C. (2004). Impact of a general practice based group parenting programme: Quantitative and qualitative results from a controlled trial at 12 months. Archives of Disease in Childhood 89(6), 519-525.

Storey, K. E., Spitters, H., Cunningham, C., Schwartz, M., \& Veugelers, P. J. (2011). Implementing comprehensive school health: Teachers' perceptions of the Alberta Project Promoting active Living and healthy Eating in Schools - APPLE Schools. PHENex Journal, 3(2), 1-18.

Taylor, S. E., \& Stanton, A. L. (2007). Coping resources, coping processes, and mental health. Annual Review of Clinical Psychology, 3, 377-401.

The Hawn Foundation. (2014). MindUP. Retrieved from http://thehawnfoundation.org/mindup/

Trinidad, D. R., \& Johnson, C. A. (2002). The association between emotional intelligence and early adolescent tobacco and alcohol use. Personality and Individual Differences, 32(1), 95-105.

Trinidad, D. R, Unger, J. B., Chou, C. P., Azen, S. P., \& Johnson, C. A. (2004). Emotional intelligence and smoking risk factors in adolescents: Interactions on smoking intentions. Journal of Adolescent Health, 34(1), 46-55.

University of Ottawa. (2014). Comprehensive School Health. Retrieved from http://uottawacomprehensive-school-health.ca

Vaillancourt, T., \& Boylan, K. (2013). Behavioural and emotional disorders of childhood and adolescence. In D. Dozois \& P. Firestone (Eds.), Abnormal psychology: Perspectives (5th ed., pp. 391-415). Toronto, ON: Pearson Education Canada.

Volk, A. A., Craig, W., Boyce, W., \& King, M. (2006). Perceptions of parents, mental health, and school amongst Canadian adolescents from the provinces and the northern territories. Canadian Journal of School Psychology, 21, 33-46.

Waddell, C., \& Shepherd, C. (2002). Prevalence of mental disorders in children and youth. Vancouver, BC: Mental Health Evaluation and Community Consultation Unit, University of British Columbia.

Weare, K., \& Markham, W. (2005). What do we know about promoting mental health through schools? Promotion \& Education, 12(3-4), 118-122.

Weare, K., \& Nind, M. (2011). Mental health promotion and problem prevention in schools: What does the evidence say? Health Promotion International, 26(S1), i29-i69.

Weissberg, R. P., \& Greenberg, M. T. (1998). School and community competence-enhancement and prevention programs. In I. E. Siegel \& K. A. Renninger (Vol. eds.), Handbook of child psychology. Vol. 4. Child psychology in practice (5th ed., pp. 877-954). New York, NY: Wiley. 
Wells, J., Barlow, J., \& Stewart-Brown, S. (2003). A systematic review of universal approaches to mental health promotion in schools. Health Education, 103, 197-220.

Whitley, J. (2010). The role of educational leaders in supporting the mental health of all students. Exceptionality Education International, 20(2), 55-69.

World Health Organization. (1986). The Ottawa charter for health promotion. Retrieved from http://www.who.int/healthpromotion/conferences/previous/ottawa/en/

World Health Organization. (2014). Mental health: Strengthening our response. Fact sheet No. 220. Retrieved from http://www.who.int/mediacentre/factsheets/fs220/en/

Yukon Education. (2014). Yukon Education Student Network. Retrieved from http://www.yesnet.yk.ca /staffroom/se_learning.html

Zins, J. E., Bloodworth, M. R., Weissberg, R. P., \& Walberg, H. J. (2007). The scientific base linking social and emotional learning to school success. Journal of Educational and Psychological Consultation. 19(2-3), 191-210.

Zubrick, S. R., \& Kovess-Masfety, V. (2005). Indicators of mental health. In H. Herrman, S. Saxena, \& R. Moodie (Eds.), Promoting mental health: Concepts, emerging evidence, practice (pp. 148-168). Geneva, Switzerland: World Health Organization.

\section{Authors' Note}

Correspondence concerning this article should be addressed to Jessica Whitley, Faculty of Education, Lamoureux Hall, 145 Jean-Jacques-Lussier Private, Ottawa, ON, K1N 6N5, Canada. Email: jwhitley@uottawa.ca 